\title{
Parliament to vote on palliative care bill
}

A vote on a private member of Parliament's bill urging the government to develop and implement a framework for improving Canadians' access to palliative care within a year is slated for the end of September.

Bill C-277, introduced in the House of Commons in May by Marilyn Gladu (Conservative, Sarnia-Lambton), was endorsed by the Canadian Medical Association (CMA) at its recent General Council in Vancouver.

The framework would include definitions of palliative care services in a variety of hospital and community settings, the required training for providers of those services and regular evaluation of the plan's effectiveness.

Gladu told CMAJ that although her riding is well served with five palliative care specialist physicians, 20 beds and "extensive" home care, fewer than $30 \%$ of Canadians have access to palliative care. Without it, Canadians don't have true choice in end of life care under the new medical assistance in dying (MAID) legislation. The limited availability of palliative care services in Canada was outlined in a recent article published in CMAJ.

This is the second attempt from within Parliament to foster palliative care in Canada. Charlie Angus MP (NDP, Timmins-James Bay) introduced a motion in 2014 calling for a pan-Canadian palliative and end-of-life care strategy. It received all-party support but no action was taken on it, Gladu says.

Health Minister Dr. Jane Philpott has often mentioned the federal government's commitment of \$3-billion toward palliative and home care, but the 2016 federal budget did not contain this specific provision as a line item, Gladu adds.

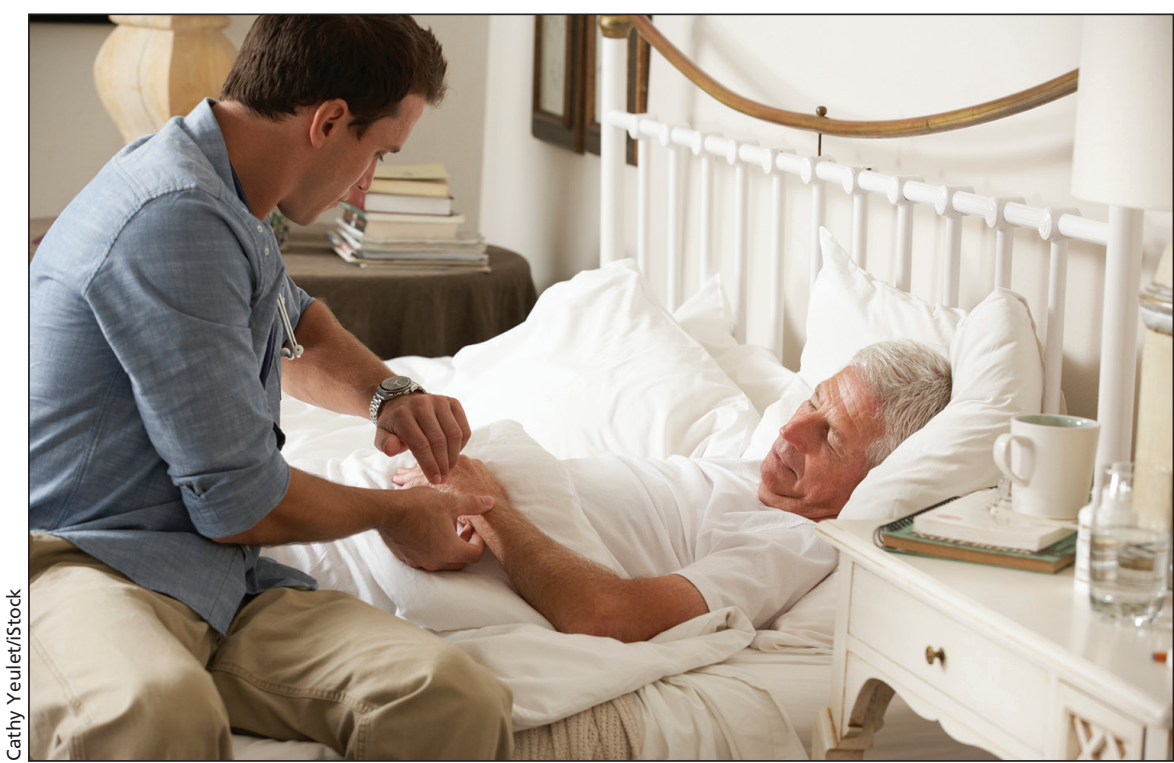

The Canadian Medical Association has endorsed a private member of Parliament's bill to improve palliative care.

Dr. Pamela Liao who put forward the motion at the CMA meeting says "No one in medicine questions palliative care as the cornerstone to managing patients who have terminal disease." Liao, who is a fellow at the Freeman Centre for the Advancement of Palliative Care at North York General Hospital, says it's likely that no action was taken by Parliament on the previous motion because the government was otherwise occupied. "They really just wanted to push MAID through. But we need to make sure that palliative care remains in the dialogue."

The Canadian Society of Palliative Care Physicians also backs Gladu's bill. "It's the first of its kind that's calling for the same thing that we've been calling for," said Dr. J. David Henderson, society president. "There's been talk about doing something for years and years - lots of talk about it but never much in the way of action."

The public awareness of end-of-life issues has increased because of the development of Canada's MAID legislation, so "if there's ever going to be a time [for a palliative care bill to pass], it's going to be now," he added.

Henderson put forward a related motion to General Council calling for the CMA to acknowledge that palliative and end-of-life care have public health implications. It, too, was endorsed.

"This is such a complex issue that touches on so many people and throughout our lives that it needs to be everybody's responsibility," Henderson says. The promotion of palliative and end-of-life care needs to be addressed even in schools and businesses in order to create "compassionate communities."

"There are not so many true communities anymore, so we're trying to bring some of that back. 'It takes a village to raise a child.' Well, where's that village when we're at the end of our lives?" Terry Murray, Toronto, Ont.

CMAJ 2016. DOI:10.1503/cmaj.109-5328 